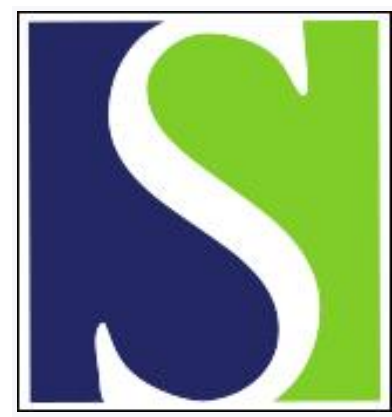

Scand J Work Environ Health 2014;40(2):195-202

https://doi.org/10.5271/sjweh.3384

Published online: 18 Sep 2013, Issue date: 01 Mar 2014

Predictors of recurrent sickness absence among workers having returned to work after sickness absence due to common mental disorders

by Arends I, van der Klink JJL, van Rhenen W, de Boer MR, Bültmann U

A broad range of possible predictors of recurrent sickness absence (SA) among workers with common mental disorders (CMD) is investigated over 12 months follow-up. The results show that work-related factors, especially conflicts with supervisor and company size $>100$ employees, rather than disease-related factors predict recurrent SA among workers who returned to work after SA due to CMD.

Affiliation: Department of Health Sciences, Community and Occupational Medicine, University Medical Center Groningen / University of Groningen, A. Deusinglaan 1, 9713 AV Groningen, the Netherlands. i.arends@umcg.nl

Refers to the following text of the Journal: 2006;32(1):67-74

The following articles refer to this text: 2015;41(5):421-424; 2020;46(1):1-4; 2022;48(5):361-371

Key terms: common mental disorder; mental health problem; predictor; prognostic factor; prospective study; recurrent sickness absence; return to work; RTW; sickness absence; sustainable return to work

This article in PubMed: www.ncbi.nlm.nih.gov/pubmed/24048675

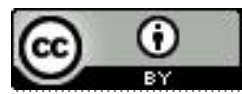




\title{
Predictors of recurrent sickness absence among workers having returned to work after sickness absence due to common mental disorders
}

\author{
by Iris Arends, MSc, ${ }^{1}$ Jac JL van der Klink, MD, PhD, ${ }^{1}$ Willem van Rhenen, MD, PhD, ${ }^{2,3}$ Michiel $R$ de \\ Boer, PhD, ${ }^{1,4}$ Ute Bültmann, PhD ${ }^{1}$
}

\begin{abstract}
Arends I, van der Klink JJL, van Rhenen W, de Boer MR, Bültmann U. Predictors of recurrent sickness absence among workers having returned to work after sick leave due to common mental disorders. Scand J Work Environ Health. 2014;40(2):195-202. doi:10.5271/sjweh.3384
\end{abstract}

Objective The aim of this study was to investigate whether sociodemographic, disease-related, personal, and work-related factors - measured at baseline - are predictors of recurrent sickness absence (SA) at 6 and 12 months follow-up among workers who returned to work after SA due to common mental disorders (CMD).

Methods Based on a cluster-randomized controlled trial, this prospective study comprised 158 participants, aged 18-63 years, with partial or full return to work (RTW) and an occupational physician-diagnosed CMD. Data on predictors were collected with questionnaires and administrative data. Outcome was the incidence of recurrent SA (ie, decreased work for $\geq 30 \%$ of contract hours due to all-cause SA regardless of partial or full RTW) at 6 and 12 months follow-up. Longitudinal logistic regression analysis with backward elimination was used.

Results We found that company size $>100$ [odds ratio (OR) $2.59,95 \%$ confidence interval $(95 \% \mathrm{CI}) 1.40-4.80$ ] and conflicts with the supervisor (OR 2.21, 95\% CI 1.21-4.04) were predictive of recurrent SA. Having $\geq 1$ chronic diseases decreased the risk of recurrent SA (OR $0.54,95 \%$ CI $0.30-0.96$ ).

Conclusions Two work- and one disease-related factor predicted the incidence of recurrent SA among workers with CMD. Healthcare providers can use these findings to detect and help workers who have returned to work and are at higher risk for recurrent SA. Furthermore, future interventions to prevent recurrent SA could focus on supervisor conflicts.

Key terms mental health problem; prognostic factor; prospective study; return to work; RTW; sustainable return to work.

Common mental disorders (CMD) (ie, depressive, anxiety, and adjustment disorders) are a frequent cause of sickness absence (SA), work disability, and reduced on-the-job productivity (1-6). Several studies have investigated predictors of first SA and return to work (RTW) among workers with CMD (7-11), but limited evidence is available on factors predicting recurrent SA among such workers. Recent studies have shown that recurrent $\mathrm{SA}$ is a frequent problem among this worker population: $20-30 \%$ of workers who returned to work after SA due to a CMD experience a recurrence of sick leave $(12,13)$. Recurrent SA due to CMD is often more serious and long-lasting than the first SA episode (12).
Additionally, frequent SA episodes are related to an increased risk of work disability in later years (14-16).

Few studies have investigated predictors for recurrent SA among workers who returned to work after SA due to CMD. Based on a Dutch register study and a large Swedish cohort study, the following risk factors were found (i) for women: age $<45$ years, married status, and low socioeconomic position; (ii) for men: age $44-55$ years and low socioeconomic position $(12,13)$. However, these two studies did not investigate other potential predictors. Several studies $(7,8,10,11,17-19)$ have identified predictors of first SA and RTW among workers with CMD, such as disease-related factors (eg,

1 Department of Health Sciences, Community and Occupational Medicine, University Medical Center Groningen / University of Groningen, Groningen, the Netherlands.

2 Center for Human Resource, Organization and Management Effectiveness, Business University Nyenrode, Breukelen, the Netherlands

3365 Occupational Health Services, Utrecht, the Netherlands.

4 Department of Health Sciences, VU University, HV Amsterdam, the Netherlands.

Correspondence to: Iris Arends, Department of Health Sciences, Community and Occupational Medicine, University Medical Center Groningen / University of Groningen, A. Deusinglaan 1, 9713 AV Groningen, the Netherlands. [E-mail: i.arends@umcg.nl] 
severity of mental health problems, problem duration, SA) and work-related factors (eg, decision authority, skill discretion, work motivation). Nevertheless, research is needed that specifically focuses on predictors of recurrent SA as these could differ from predictors for first SA. For example, workers might have had treatment or guidance after the first SA period, and work accommodations might have been installed to enable RTW. Such actions probably reduce the predictive effect of risk factors for first SA. The question remains which factors are predictive for recurrent SA. Therefore, the goal of this prospective study was to investigate whether sociodemographic, disease-related, personal, and workrelated factors predict recurrent SA among workers who partially or fully returned to work after SA due to CMD.

\section{Methods}

\section{Study population}

Occupational physicians (OP) working for a large Dutch occupational health service (OHS) - based in different regions of the Netherlands and working for companies of different sizes in various sectors recruited participants from January 2010 to June 2011. Study inclusion criteria were: (i) age 18-63 years; (ii) employed in a paid job; (iii) OP-diagnosed CMD (based on ICD-10 codes F32.9, F41.9, F43.1, F43.9, R45, and Z73.0) at the start of the SA episode; (iv) SA for $\geq 2$ consecutive weeks from the start of SA (to exclude short SA with relatively little impact); and (v) RTW within two weeks at the moment of inclusion (to ensure that participants were at risk for recurrent SA). Workers were excluded if they: (i) had an SA episode $>12$ months from the start of SA; (ii) had prior SA episode due to CMD in past three months before the present episode; (iii) suffered from severe mental disorders, such as psychotic disorder or bipolar disorder; (iv) presented OP-assessed (using the Dutch coding system based on ICD-10) somatic complaints/ disorders that affect RTW (20); (v) were pregnant, or facing upcoming retirement/resignation/lay-off; and (vi) were unable to read, write, and understand Dutch.

A total of 212 workers were recruited, of which 54 (25\%) declined participation. Those declining participation did not significantly differ from those who agreed to participate with respect to gender $(59 \%$ of the responders were female compared to $63 \%$ of the non-responders, $\mathrm{P}=0.60$ ) and age [responders mean age was 2.2 years higher, standard deviation (SD) $1.8, \mathrm{P}=0.21$ ]. The total study sample consisted of 158 participants ( 80 participants in the intervention group and 78 in the control group). For the analyses, one participant was excluded due to missing data on all variables, and at 6 and 12 months follow-up, respectively, 11 and 12 participants had to be excluded due to missing administrative data on $\mathrm{SA}(\mathrm{N}=146$ and $\mathrm{N}=147$, respectively).

\section{Procedure}

Data were collected in the context of a cluster randomized controlled trial (RCT) in which problem-solving OP treatment was compared to OP care-as-usual (CAU) on effectiveness in preventing recurrent SA among workers who returned to work after SA due to CMD (Arends et al, submitted for publication). Participants received the baseline questionnaire when they had resumed work for 2-4 weeks (22 participants had full RTW while all others had partial RTW). The questionnaire was constructed for both the cluster RCT and the present study. More detailed information on study design, setting, and the intervention can be found elsewhere (21). The Medical Ethical Board of the University Medical Center Groningen approved the study.

\section{Predictors}

Based on previous research $(8,11,12,18,22)$, the following potential predictors were examined:

Sociodemographic factors. We assessed sex, age, educational level (low/medium/high), and cohabiting (yes/ no) characteristics.

Disease-related factors. The 14-item self-report Hospital Anxiety and Depression Scale (HADS) was used to assess depression (7 items) and anxiety (7 items). Item scores range from $0-3$ with higher scores indicating more symptoms $(23,24)$. Distress symptoms were assessed with the 16-item distress scale of the Four-Dimensional Symptom Questionnaire (4DSQ) with scores ranging from $0=$ no to $2=$ frequently, often or very often $(25,26)$. All mental health measures were dichotomized at the cut-off score for clinical relevance ( 8 for HADS and 20 for the distress scale) $(27,28)$. Data on psychopharmacological medication use (yes/no) was collected with the Trimbos/iMTA questionnaire for Costs associated with Psychiatric Illness (Tic-P) (29). SA duration (in days) of the present SA episode at baseline was obtained from the OHS registry and divided into tertiles because of the skewed data. General health was assessed with one question from the 36-item Short-Form Heath Survey (SF-36): "In general, how would you rate your health?" The response categories were dichotomized to excellent, very good, good, versus fair or poor (30). Participants were also asked if they had $\geq 1$ physical and/or mental chronic diseases (yes/no). 
Personal factors. Coping behavior was assessed with the 14-item Utrecht Coping List (31). The questionnaire consists of three scales: (i) active problem-focused coping, (ii) emotional coping, and (iii) avoidance coping. Item scores range from 1="seldom or never" to $4=$ ="very often" with lower scores indicating infrequent use of a certain coping behavior.

Work-related factors. Work status was assessed by questionnaire data on tenure $(0-5$ years versus $>5$ years), contract type (temporary versus permanent), company size $(<100$ versus $\geq 100$ ), supervisor (yes versus no), monthly income in euros, work accommodations for RTW (yes versus no), and consultations with OP in the past month $(0,1,>1)$. Based on administrative data from the OHS' registry, we collected data on RTW percentage at the start of RTW and at baseline (2-4 weeks after RTW started).

Work functioning was assessed with the 27-item Work Role Functioning Questionnaire $(32,33)$. Response categories ranged from $100 \%$ (all of the time) to $0 \%$ (never), with an option to score "not applicable." Scores were converted to a total score between $0-100$, with higher scores indicating better work functioning.

Work engagement was assessed with the 9-item Utrecht Work Engagement Scale. Item scores range from $0=$ "never" to $6=$ "always" with higher scores indicating greater work engagement $(34,35)$.

Readiness to stay at work was assessed with the Stay At Work subscale (6 items) part of the Readiness to Return to Work Scale (36). Item scores range from $0=$ "totally disagree" to $4=$ "totally agree" with higher scores indicating greater readiness to stay at work.

Work-related psychosocial factors (ie, decision latitude, psychological job demands, supervisor social support, and coworker social support) were measured with the Job Content Questionnaire (37-39). Scores were divided into tertiles. Conflicts with colleagues and supervisors were both measured with one question from the Dutch Questionnaire on Perception and Judgment of Work (40) and dichotomized to "never" versus "sometimes", "often or always". Job insecurity was assessed with one question: "Are you afraid to lose your job within the near future?" (yes versus no).

\section{Outcome}

Recurrent SA (yes versus no) was examined at 6 and 12 months follow-up. Recurrent SA was defined as a decrease in work for $\geq 30 \%$ of the contract hours due to all-cause SA, regardless of partial or full RTW. For example, participants with partial RTW $(50 \%$ of the contract hours) who reduced their working time to $20 \%$ of the contract hours and participants with full RTW ( $100 \%$ of the contract hours) who reduced their working time to $70 \%$ were both registered as having recurrent SA. Following this, participants became at risk for a recurrence as from $30 \%$ RTW (2-3 weeks after baseline all participants had $\geq 30 \%$ RTW).

\section{Statistical analysis}

To identify predictors of recurrent SA at 6 and 12 months follow-up, univariable and multivariable logistic Generalized Estimating Equations (GEE) analyses with exchangeable correlation matrices were conducted to take the random effects (ie, measurements over time) at the participant level into account. Random effects at the OP level were examined in a mixed model but these did not improve model fit and were not included in the analyses. The intervention and control groups were combined in the analyses. To investigate whether the intervention modified the relation between the predictor and the outcome variable, treatment type $x$ predictor interactions were analyzed (41). We first identified predictors with a P-value $\leq 0.20$ in univariable analyses for inclusion in a multivariable model (42). Subsequently, we tested interactions between each of these predictors and treatment type (problem-solving treatment or CAU) in univariable models. Interaction terms with a P-value $\leq 0.20$ were also included in the multivariable model. In the multivariable model, a backward selection procedure was used until the model only contained variables with P-values of $<0.05$ (42). Dummy variables were included when at least one of the dummies had a P-value $<0.05$ and when the model fit did not decrease due to the dummy variable. Treatment type was included as a covariate for the univariable and multivariable analyses. For the final multivariable model, interactions with time were tested to examine whether the strength of associations between predictors and recurrent SA differed at 6 and 12 months follow-up. In a sensitivity analysis, a multivariable model with a P-value $<0.10$ was analyzed. Furthermore, to adjust for the influence of baseline SA on recurrent SA, two additional analyses were conducted: one with baseline duration of SA as covariate and one with baseline RTW percentage as covariate. All analyses were performed in SPSS version 20.0 (SPSS Institute, Chicago, IL, USA).

\section{Results}

\section{Sample characteristics}

Baseline values for potential predictors are presented in table 1. Between baseline and 6 months follow-up, 51 participants experienced recurrent SA (cumulative 6-month incidence: 32\%) while, between 6 and 12 
Table 1. Baseline characteristics of study population ( $N=158)$. [4DSQ=four-dimensional symptom questionnaire; HADS=hospital anxiety and depression scale; IQR=interquartile range (25$75 \%$ ); JCQ=job content questionniare; $\mathrm{OP}=0$ ccupational physician; RSAW=readiness to stay at work; RTW=return to work; $\mathrm{SA}=$ sickness absence; $\mathrm{SD}=$ standard deviation; $\mathrm{UCL}=$ Utrecht coping list; WRFQ=work role functioning questionnaire;]

\begin{tabular}{|c|c|c|c|c|c|c|}
\hline Factors & $\mathrm{N}$ & $\%$ & Mean & SD 1 & Median & IQR \\
\hline \multicolumn{7}{|l|}{ Sociodemographic } \\
\hline Gender (male) & 65 & 41 & & & & \\
\hline \multicolumn{7}{|l|}{ Age } \\
\hline Educational level & & & 42.3 & 9.6 & & \\
\hline Low & 19 & 12 & & & & \\
\hline Medium & 76 & 48 & & & & \\
\hline High & 61 & 39 & & & & \\
\hline Cohabiting, yes & 126 & 80 & & & & \\
\hline \multicolumn{7}{|l|}{ Disease-related } \\
\hline $\begin{array}{l}\text { General health (poor } \\
\text { or very poor) }\end{array}$ & 45 & 29 & & & & \\
\hline$\geq 1$ chronic diseases (yes) & 82 & 52 & & & & \\
\hline \multicolumn{7}{|l|}{ HADS scores $(0-21)$} \\
\hline Anxiety & & & 7.5 & 3.7 & & \\
\hline Depression & & & 7.1 & 4.4 & & \\
\hline 4DSQ distress score (0-32) & & & 14.7 & 7.5 & & \\
\hline $\begin{array}{l}\text { Psychopharmacologic } \\
\text { medication use }\end{array}$ & 39 & 25 & & & & \\
\hline Duration of SA & & & & & 101.8 & $59.3-145.1$ \\
\hline \multirow{2}{*}{\multicolumn{7}{|c|}{$\begin{array}{l}\text { Personal } \\
\text { UCL subscale scores (type } \\
\text { of coping) }\end{array}$}} \\
\hline & & & & & & \\
\hline Problem-focused (5-20) & & & 13.2 & 3.1 & & \\
\hline Emotional (5-20) & & & 10.4 & 2.7 & & \\
\hline Avoidance (4-16) & & & 8.7 & 1.9 & & \\
\hline \multicolumn{7}{|l|}{ Work-related } \\
\hline Tenure ( $0-5$ years) & 69 & 44 & & & & \\
\hline Contract type (permanent) & 150 & 95 & & & & \\
\hline Company size $(<100)$ & 62 & 39 & & & & \\
\hline Supervising role & 44 & 28 & & & & \\
\hline Monthly income (euros) & & & & & 1750 & $1300-2100$ \\
\hline Accommodation for RTW & 109 & 69 & & & & \\
\hline \multicolumn{7}{|c|}{ Number of OP consultations } \\
\hline 0 & 20 & 13 & & & & \\
\hline 1 & 91 & 58 & & & & \\
\hline$>1$ & 43 & 27 & & & & \\
\hline \multicolumn{7}{|l|}{ RTW percentage } \\
\hline At start of RTW & & & & & 40.0 & $22.0-63.0$ \\
\hline At baseline & & & & & 25.0 & $0.0-50.0$ \\
\hline WRFQ total score $(0-100)$ & & & 63.6 & 18.4 & & \\
\hline Work engagement $(0-6)$ & & & 3.3 & 1.3 & & \\
\hline RSAW total score $(0-24)$ & & & 20.4 & 3.7 & & \\
\hline \multicolumn{7}{|l|}{ JCQ subscale scores } \\
\hline Decision latitude & & & 67.58 & 10.4 & & \\
\hline Psychological job demands & & & 33.9 & 6.6 & & \\
\hline Supervisor social support & & & 10.6 & 2.5 & & \\
\hline Colleague social support & & & 12.0 & 1.6 & & \\
\hline $\begin{array}{l}\text { Conflicts with colleagues } \\
\text { (never) }\end{array}$ & 76 & 48 & & & & \\
\hline $\begin{array}{l}\text { Conflicts with supervisor } \\
\text { (never) }\end{array}$ & 75 & 48 & & & & \\
\hline Job insecurity (yes) & 20 & 13 & & & & \\
\hline
\end{tabular}

months follow-up, this increased to 59 participants (cumulative 6-month incidence: $37 \%$ ). A total of 33 $(23 \%)$ participants experienced recurrent SA between both baseline and 6 months follow-up and 6 and 12 months follow-up, and 69 (47\%) participants experienced no recurrence during each of these periods.

\section{Predictors of recurrent sickness absence}

In the univariable GEE analyses, 11 potential predictors showed a P-value of $\leq 0.20$ (table 2). Significant interactions with treatment group were shown for psychopharmacologic medication use and supervisor social support. Thus, 11 potential predictors and two interactions were entered into the multivariable GEE model. After backward elimination, the final multivariable model contained one disease-and two work-related predictors (table 2). Company size $>100$ workers [odds ratio (OR) $2.59,95 \%$ confidence interval $(95 \% \mathrm{CI}) 1.40-5.80]$ and conflicts with supervisor (OR 2.21, 95\% CI 1.21-4.04) increased the risk of recurrent SA. Reporting $\geq 1$ chronic diseases (OR 0.54, 95\% CI 0.30-0.96) decreased the risk of recurrent SA. None of these predictors had significant interactions with treatment group or time.

Sensitivity analysis with a P-value of $<0.10$ for the multivariable model resulted in one extra work-related predictor, supervisor social support, which showed a significant interaction with treatment type and was only predictive for the control group (and therefore not presented in the table). For workers in the control group, those in the highest tertile of supervisor social support scores had a lower risk of recurrent SA compared to workers in the lowest tertile (OR $0.28,95 \% \mathrm{CI}$ 0.07-1.14), while for the intervention group there was no statistically significant effect of supervisor social support at the $\mathrm{P}<0.10$ level.

Two additional analyses with baseline duration of SA and baseline RTW percentage as covariates did not change the results.

\section{Discussion}

The goal of this study was to identify predictors of recurrent SA among workers who returned to work after SA due to CMD. The multivariable analyses revealed three main predictors for recurrent SA at 6 and 12 months follow-up: company size $>100$ workers and conflicts with supervisor increased the odds of recurrent $\mathrm{SA}$, while $\geq 1$ chronic diseases decreased the odds. The finding that $>30 \%$ of the study population experienced recurrent SA underlines the importance of focusing on these factors to monitor workers who returned to work after SA due to $\mathrm{CMD}$ in order to prevent SA from reoccuring. 
Two previous studies have investigated predictors of recurrent SA among workers with $\operatorname{CMD}(12,13)$. Comparisons with these studies are, however, hampered because the studies were based on register data and did not include a great variety of predictors. Koopmans et al (43) examined the effect of sex and age on recurrent SA and did not find differences between men and women which is comparable to our results. The authors did find an age effect for women and showed that women aged $<35$ years and 35-44 years were at greater risk of recurrent SA. Due to the small sample size of our study, we were unable to conduct gender-specified analyses. Virtanen et al (13) primarily investigated the effect of socioeconomic position on recurrent SA and found that manual occupations had a significantly higher risk of recurrent SA compared to higher, non-manual occupations. In the present study, no data on type of occupations were available. Educational level and income were included as proxy measures, but both measures were not significantly associated with recurrent SA. When comparing our results with studies that have investigated predictors of SA among workers with CMD, some differences can be observed. From several studies, it is known that older age and also the severity of mental health problems (eg, depression severity, comorbidity, duration of the problems) predict longer SA $(9,11,19$, $22,44)$. Our results showed that both age and symptom severity did not predict recurrent SA. The present study showed for the first time that conflicts with the supervisor is a predictor of recurrent SA. This factor has not been frequently investigated in prognostic studies on SA although OP, psychologists, and workers have stressed the role of the supervisor in the RTW process $(45,46)$. Studies on work-related predictors for CMD have taken conflicts with coworkers and supervisors into account, showing they were predictive of CMD $(47,48)$. Additionally, these studies found that low supervisor support predicted CMD (47-49), which we found was also predictive of recurrent SA for the control group. Thus, predictors of recurrent SA among workers with CMD seem to be more similar to predictors of CMD than to predictors of first time SA among workers with CMD.

\section{Strengths and limitations}

The strengths of this study are its prospective design and the inclusion of participants based on OP diagnoses rather than self-report. An additional strength is the use of registry data to measure the incidence of recurrent SA at different time points, which allowed us to examine phase-specificity of predictors. Furthermore, the study is the first of its kind examining a wide variety of factors (in different domains) for the prediction of recurrent SA among workers who returned to work after SA due to CMD.
Table 2. Predictors of recurrent sickness absence at 6 and 12 months ( $\mathrm{N}=146)$. [ $95 \% \mathrm{Cl}=95 \%$ confidence interval; JCQ=job content questionniare; $\mathrm{OR}=0 \mathrm{dds}$ ratio; $\mathrm{RTW}=$ return to work]

\begin{tabular}{|c|c|c|c|c|c|c|c|}
\hline \multirow[t]{2}{*}{ Predictor } & \multirow[t]{2}{*}{$\mathrm{N}$} & \multicolumn{3}{|c|}{$\begin{array}{l}\text { Univariable } \\
\text { analyses a }\end{array}$} & \multicolumn{3}{|c|}{$\begin{array}{l}\text { Multivariable } \\
\text { regression model a }\end{array}$} \\
\hline & & $\mathrm{OR}$ & $95 \% \mathrm{Cl}$ & $\begin{array}{c}\mathrm{P}- \\
\text { value }\end{array}$ & $\mathrm{OR}$ & $95 \% \mathrm{Cl}$ & $\begin{array}{c}\mathrm{P}- \\
\text { value }^{\mathrm{b}}\end{array}$ \\
\hline \multicolumn{8}{|l|}{$\begin{array}{l}\text { Sociodemographic } \\
\text { factors } \\
\text { Cohabiting }\end{array}$} \\
\hline Yes & 118 & 1.00 & & & & & \\
\hline No & 27 & 1.64 & $0.88-3.07$ & 0.12 & & & \\
\hline \multicolumn{8}{|l|}{$\begin{array}{l}\text { Disease-related } \\
\text { factors } \\
\text { Psychopharma- } \\
\text { cologic medica- } \\
\text { tion use }\end{array}$} \\
\hline No & 103 & 1.00 & & & & & \\
\hline $\begin{array}{l}\text { Yes } \\
\geq 1 \text { chronic } \\
\text { diseases }\end{array}$ & 39 & 1.78 & $0.93-3.40$ & 0.08 & & & \\
\hline No & 70 & 1.00 & & & 1.00 & & \\
\hline Yes & 75 & 0.60 & $0.34-1.05$ & 0.07 & 0.54 & $0.30-0.96$ & 0.04 \\
\hline \multicolumn{8}{|l|}{$\begin{array}{l}\text { Work-related } \\
\text { factors }\end{array}$} \\
\hline \multicolumn{8}{|l|}{ Company size } \\
\hline$<100$ & 60 & 1.00 & & & 1.00 & & \\
\hline$\geq 100$ & 85 & 2.09 & $1.15-3.80$ & 0.02 & 2.59 & $1.40-4.80$ & 0.00 \\
\hline \multicolumn{8}{|l|}{$\begin{array}{l}\text { RTW percentage } \\
\text { at baseline }\end{array}$} \\
\hline $0-12$ & 48 & 1.00 & & & & & \\
\hline $13-49$ & 46 & 1.52 & $0.73-3.20$ & 0.27 & & & \\
\hline \multirow{2}{*}{\multicolumn{8}{|c|}{ JCQ subscale }} \\
\hline & & & & & & & \\
\hline \multicolumn{8}{|l|}{ scores } \\
\hline \multicolumn{8}{|l|}{$\begin{array}{l}\text { Supervisor } \\
\text { social support }\end{array}$} \\
\hline $0-9$ & 43 & 1.00 & & & & & \\
\hline $10-12$ & 81 & 0.56 & $0.29-1.08$ & 0.08 & & & \\
\hline$>12$ & 18 & 0.55 & $0.20-1.54$ & 0.26 & & & \\
\hline \multicolumn{8}{|l|}{$\begin{array}{l}\text { Colleague } \\
\text { social support }\end{array}$} \\
\hline $0-11$ & 32 & 1.00 & & & & & \\
\hline 12 & 68 & 0.60 & $0.31-1.17$ & 0.14 & & & \\
\hline$>12$ & 42 & 0.66 & $0.28-1.52$ & 0.32 & & & \\
\hline \multicolumn{8}{|l|}{$\begin{array}{l}\text { Conflicts with } \\
\text { supervisor }\end{array}$} \\
\hline Never & 71 & 1.00 & & & 1.00 & & \\
\hline $\begin{array}{l}\text { Sometimes, } \\
\text { often or always }\end{array}$ & 73 & 1.67 & $0.95-2.95$ & 0.08 & & $11.21-4.04$ & 0.01 \\
\hline
\end{tabular}

a Adjusted for treatment group.

b $\mathrm{P}<0.05$

c Participants with a RTW of $<30 \%$ at baseline progressed to a RTW of $\geq 30 \%$ within $2-3$ weeks after baseline and were, therefore, also at risk for recurrent sickness absence.

A limitation of the study is the relatively small sample size, which has restricted the power to detect (and rule out) relevant predictors. A careful interpretation of our findings is required in light of this. The sensitivity analysis showed that when increasing the power of the study by applying a P-value $<0.10$, an extra predictor was included in the final multivariable model. As this sensitivity analysis increased the chances of a Type-I error, future studies should include more participants. The small sample size also forced us to dichotomize 
several categorical variables, thereby losing important information. This might have led to underestimations of the associations under study. Another limitation is that we only assessed possible predictor variables at baseline, while some of these variables may have changed during the 12-month follow-up. For example, workers whose work changed or who were moved to a different department might have experienced changes in job demands and social support at work that we would not have captured. The generalizability of the findings may be somewhat restricted as participants were selected for a cluster RCT based on specific eligibility criteria. Still, we included workers with a broad range of mental health complaints, working in small-to-large companies and different sectors, which improves the generalizability. Furthermore, our definition of recurrence (ie, decreased work for $30 \%$ of the contract hours) will not be transferable to countries where RTW is not as gradually built up. However, this definition enabled us to take into account a substantial reduction in work hours during the RTW process instead of only looking at recurrence after full RTW, which would overlook a problematic RTW process. Finally, even though a broad range of factors was included in this study, there might be some unmeasured constructs, such as previous SA episodes (50), which impact recurrent SA.

\section{Implications for research and practice}

Although a predictor such as company size cannot be modified, healthcare providers can use our results to identify and follow workers at greater risk of recurrent SA. Employee conflicts with supervisors are more amendable to change as healthcare providers can help the worker to deal with such conflict adequately. This might be especially important if conflicts with the supervisor were also related to the initial CMD SA episode. In the future design of interventions to prevent recurrent SA, a treatment component might be incorporated focusing on how to deal with supervisor conflicts. Somewhat unexpectedly, we found that having $\geq 1$ chronic diseases was predictive of reduced incident-recurrent SA. A possible explanation might be that workers who have succeeded in returning to work despite chronic diseases have acquired more experience in dealing with health-related problems that hinder work functioning and are better equipped to prevent recurrent SA (eg, more knowledgeable and competent in asking for help to overcome work-related problems). Finally, we found that working in a small company was protective for the incidence of recurrent SA. This might be counterintuitive as larger companies have more resources to accommodate workers that have health-related work functioning problems. However, work accommodations were also included in the analyses but not found to be predictive of recurrent SA. A possible explanation for the protective effect of small companies might be that workers in such companies experience more commitment and responsibility towards colleagues and the employer, greater supervisor support is provided, and the impact of the worker's behavior on others (eg, SA) is more visible. In the present study, no information on organizational commitment was included. Another explanation could be that company size is a proxy for a factor that is related to recurrent SA (eg, mental demands). However, in our study, the subscale psychological job demands of the Job Content Questionnaire was not related to recurrent SA. Possibly a different factor related to company size and recurrent SA, but not measured in our study, explains our results. Thus, future studies should include variables on organizational commitment and think of other possible explanatory factors to further investigate the relationship we found between company size and recurrent SA.

\section{Concluding remarks}

This study found that company size $>100$ workers and conflicts with supervisor increased the odds of recurrent SA at 6 and 12 months follow-up, while $\geq 1$ chronic diseases decreased the odds among workers who have returned to work after SA due to CMD. Factors related to symptom severity did not predict recurrent SA. As this is the first study that has investigated a broad range of predictors for recurrent SA among workers with CMD and consisted of a small study population, our results should be interpreted carefully. Future studies with larger study populations are needed to investigate predictors of recurrent SA in this worker population to corroborate our findings.

\section{Acknowledgements}

Stichting Instituut GAK, a Dutch funding agency, supported this project with a grant. The authors were independent of the funders and the funders had no role in the project. The authors declare no conflicts of interest.

\section{References}

1. Sanderson K, Andrews G. Common mental disorders in the workforce: Recent findings from descriptive and social epidemiology. Can J Psychiatry. 2006;51(2):63-75.

2. Stansfeld SA, Fuhrer R, Head J. Impact of common mental disorders on sickness absence in an occupational cohort study. Occup Environ Med. 2011 Jun;68(6):408-13. http://dx.doi. org/10.1136/oem.2010.056994. 
3. Alonso J, Angermeyer MC, Bernert S, Bruffaerts R, Brugha TS, Bryson H, et al. Disability and quality of life impact of mental disorders in europe: Results from the european study of the epidemiology of mental disorders (ESEMeD) project. Acta Psychiatr Scand Suppl. 2004(420):38-46.

4. Rai D, Skapinakis P, Wiles N, Lewis G, Araya R. Common mental disorders, subthreshold symptoms and disability: Longitudinal study. Br J Psychiatry. 2010 Nov;197:411-2. http://dx.doi.org/10.1192/bjp.bp.110.079244.

5. Stewart WF, Ricci JA, Chee E, Hahn SR, Morganstein D. Cost of lost productive work time among US workers with depression. JAMA. 2003;289(23):3135-44.

6. Goetzel RZ, Long SR, Ozminkowski RJ, Hawkins K, Wang S, Lynch W. Health, absence, disability, and presenteeism cost estimates of certain physical and mental health conditions affecting U.S. employers. J Occup Environ Med. 2004;46(4):398-412.

7. Norlund S, Reuterwall C, Höög J, Nordin M, Edlund C, Slunga Birgander L. Work related factors and sick leave after rehabilitation in burnout patients: Experiences from the REST-project. J Occup Rehabil. 2011 Mar;21(1):23-30. http:// dx.doi.org/10.1007/s10926-010-9250-8.

8. Blank L, Peters J, Pickvance S, Wilford J, Macdonald E. A systematic review of the factors which predict return to work for people suffering episodes of poor mental health. J Occup Rehabil. 2008 Mar;18(1):27-34. http://dx.doi.org/10.1007/ s10926-008-9121-8.

9. Cornelius LR, van der Klink JJ, Groothoff JW, Brouwer S. Prognostic factors of long term disability due to mental disorders: A systematic review. J Occup Rehabil. 2011 Jun;21(2):259-74. http://dx.doi.org/10.1007/s10926-0109261-5.

10. Nielsen MB, Bultmann U, Madsen IE, Martin M, Christensen U, Diderichsen F, et al. Health, work, and personal-related predictors of time to return to work among employees with mental health problems. Disabil Rehabil. 2012;34(15):1311-6. http://dx.doi.org/10.3109/09638288.2011.641664.

11. Brouwers EP, Terluin B, Tiemens BG, Verhaak PF. Predicting return to work in employees sick-listed due to minor mental disorders. J Occup Rehabil. 2009 Dec;19(4):323-32. http:// dx.doi.org/10.1007/s10926-009-9198-8.

12. Koopmans PC, Bultmann U, Roelen CA, Hoedeman R, van der Klink JJ, Groothoff JW. Recurrence of sickness absence due to common mental disorders. Int Arch Occup Environ Health. 2011 Feb;84(2):193-201. http://dx.doi.org/10.1007/s00420010-0540-4.

13. Virtanen M, Kawachi I, Oksanen T, Salo P, Tuisku K, Pulkki-Raback L, et al. Socio-economic differences in long-term psychiatric work disability: Prospective cohort study of onset, recovery and recurrence. Occup Environ Med. 2011 Nov;68(11):791-8. http://dx.doi.org/10.1136/ oem.2010.061101.

14. Reis RJ, Utzet M, La Rocca PF, Nedel FB, Martin M, Navarro A. Previous sick leaves as predictor of subsequent ones. Int Arch Occup Environ Health. 2011 Jun;84(5):491-9. http:// dx.doi.org/10.1007/s00420-011-0620-0.
15. Koopmans PC, Roelen CA, Groothoff JW. Frequent and long-term absence as a risk factor for work disability and job termination among employees in the private sector. Occup Environ Med. 2008 Jul;65(7):494-9. http://dx.doi. org/10.1136/oem.2007.034322.

16. Labriola M, Lund T. Self-reported sickness absence as a risk marker of future disability pension. prospective findings from the DWECS/DREAM study 1990-2004. Int J Med Sci. 2007 May;4(3):153-8. http://dx.doi.org/10.7150/ijms.4.153.

17. Flach PA, Groothoff JW, Krol B, Bultmann U. Factors associated with first return to work and sick leave durations in workers with common mental disorders. Eur J Public Health. 2012 Jun;22(3):440-5. http://dx.doi.org/10.1093/eurpub/ ckr102.

18. Nieuwenhuijsen K, Verbeek JH, de Boer AG, Blonk RW, van Dijk FJ. Predicting the duration of sickness absence for patients with common mental disorders in occupational health care. Scand J Work Environ Health. 2006;32(1):67-74. http:// dx.doi.org/10.5271/sjweh.978.

19. Hees HL, Koeter MW, Schene AH. Predictors of longterm return to work and symptom remission in sicklisted patients with major depression. J Clin Psychiatry. 2012 Aug;73(8):e1048-55. http://dx.doi.org/10.4088/ JCP. $12 \mathrm{~m} 07699$.

20. UWV. Dutch Workers IA. CAS. classificaties voor arbo en SV classificatie van klachten, ziekten en oorzaken voor bedrijfsen verzekeringsartsen. [CAS. classifications for occupational health services and social security. classification of complaints, diseases, and causes for occupational health and social security physicians]. Amsterdam: UWV; 2002.

21. Arends I, van der Klink JJ, Bultman U. Prevention of recurrent sickness absence among employees with common mental disorders NTR1963. BMC Public Health. 2010;10:132. http:// dx.doi.org/10.1186/1471-2458-10-132.

22. Lagerveld SE, Bultmann U, Franche RL, van Dijk FJ, Vlasveld MC, van der Feltz-Cornelis CM, et al. Factors associated with work participation and work functioning in depressed workers: A systematic review. J Occup Rehabil. 2010 Sep;20(3):27592. http://dx.doi.org/10.1007/s10926-009-9224-x.

23. Andrea H, Bultmann U, Beurskens AJ, Swaen GM, van Schayck CP, Kant IJ. Anxiety and depression in the working population using the HAD scale--psychometrics, prevalence and relationships with psychosocial work characteristics. Soc Psychiatry Psychiatr Epidemiol. 2004;39(8):637-46. http:// dx.doi.org/10.1007/s00127-004-0797-6.

24. Spinhoven P, Ormel J, Sloekers PP, Kempen GI, Speckens AE, Van Hemert AM. A validation study of the hospital anxiety and depression scale (HADS) in different groups of dutch subjects. Psychol Med. 1997;27(2):363-70.

25. Terluin B, Van Rhenen W, Schaufeli WB, De Haan M. The four-dimensional symptom questionnaire (4DSQ): Measuring distress and other mental health problems in a working population. Work \& Stress. 2004;18(3):187-207. http:// dx.doi.org/10.1080/0267837042000297535.

26. Terluin B, van Marwijk HW, Ader HJ, de Vet HC, Penninx 
BW, Hermens ML, et al. The four-dimensional symptom questionnaire (4DSQ): A validation study of a multidimensional self-report questionnaire to assess distress, depression, anxiety and somatization. BMC Psychiatry. 2006;6:34.

27. Terluin B, Brouwers EP, van Marwijk HW, Verhaak PF, van der Horst HE. Detecting depressive and anxiety disorders in distressed patients in primary care; comparative diagnostic accuracy of the four-dimensional symptom questionnaire (4DSQ) and the hospital anxiety and depression scale (HADS). BMC Fam Pract. 2009 Aug 23;10:58. http://dx.doi. org/10.1186/1471-2296-10-58.

28. Terluin B. De vierdimensionale klachtenlijst (4DKL) in de huisartspraktijk. psychodiagnostisch gereedschap. [The four-dimensional symptom questionnaire (4DSQ) in general practice. pyschodiagnostic tools.]. De Psycholoog. 1998;33:18-24.

29. Hakkart-van Roijen L. Manual Trimbos/iMTA questionnaire for costs associated with psychiatric illness (TiC-P). Rotterdam: Institute for Medical Technology Assessment; 2002.

30. Aaronson NK, Muller M, Cohen PD, Essink-Bot ML, Fekkes $\mathrm{M}$, Sanderman R, et al. Translation, validation, and norming of the dutch language version of the SF-36 health survey in community and chronic disease populations. J Clin Epidemiol. 1998 Nov;51(11):1055-68. http://dx.doi.org/10.1016/S08954356(98)00097-3.

31. Schreurs PJG, van dW, Brosschot JF, Tellegen B, Graus GMH. De utrechtse copinglijst: UCL. [The Utrecht coping list: UCL]. Lisse: Swets en Zeitlinger b.v; 1993.

32. Abma FI, Amick Iii BC, Brouwer S, van der Klink JJ, Bultmann U. The cross-cultural adaptation of the work role functioning questionnaire to dutch. Work. 2012;43(2):203-10.

33. Abma FI, van der Klink JJ, Bultmann U. The work role functioning questionnaire 2.0 (dutch version): Examination of its reliability, validity and responsiveness in the general working population. J Occup Rehabil. 2013 Mar;23(1):13547. http://dx.doi.org/10.1007/s10926-012-9379-8.

34. Schaufeli WB, Bakker AB. Bevlogenheid: Een begrip gemeten. [Work engagement: The measurement of a concept]. Gedrag \& Organisatie. 2004;17(2):89-112.

35. SchaufeliWB, BakkerAB, Salanova M. The measurement of work engagement with a short questionnaire: A cross-national study. Educational and Psychological Measurement. 2006;66:701-16. http://dx.doi.org/10.1177/0013164405282471.

36. Franche RL, Corbiere M, Lee H, Breslin FC, Hepburn CG. The readiness for return-to-work (RRTW) scale: Development and validation of a self-report staging scale in lost-time claimants with musculoskeletal disorders. J Occup Rehabil. 2007 Sep;17(3):450-72. http://dx.doi.org/10.1007/s10926-0079097-9.

37. Houtman I. Reliability and validity of the dutch version of the karasek job content questionnaire. APA/NIOSH conference on work, stress and health; Washington, DC.; 1995.

38. Karasek RA. Job demands, job decision latitude, and mental strain: Implications for job redesign. Adm Sci Q. 1979;24(2):285-308.
39. Karasek RA. Job content questionnaire and users's guide. Los Angelos (CA): University of Southern California: Department of Industrial and Systems Enigeneering; 1985.

40. van Veldhoven M, Meijman T. Het meten van psychosociale arbeidsbelasting met een vragenlijst: De vragenlijst beleving en beoordeling van de arbeid (VBBA). [Questionnaire on perception and judgement of work]. Amsterdam: NIA; 1994.

41. Moons KG, Royston P, Vergouwe Y, Grobbee DE, Altman DG Prognosis and prognostic research: What, why, and how? BMJ. 2009 Feb 23;338:b375. http://dx.doi.org/10.1136/bmj.b375.

42. Twisk JWR. Inleiding in de toegepaste biostatistiek [Introduction to applied biostatistics]. Amsterdam: Elsevier gezondheidszorg; 2010.

43. Koopmans PC, Roelen CA, Bultmann U, Hoedeman R, van der Klink JJ, Groothoff JW. Gender and age differences in the recurrence of sickness absence due to common mental disorders: A longitudinal study. BMC Public Health. 2010 Jul;10:426. http://dx.doi.org/10.1186/1471-2458-10-426.

44. Catalina-Romero C, Pastrana-Jimenez JI, Tenas-Lopez MJ, Martinez-Munoz P, Ruiz-Moraga M, Fernandez-Labandera C, et al. Long-term sickness absence due to adjustment disorder. Occup Med (Lond). 2012 Jul;62(5):375-8. http://dx.doi. org/10.1093/occmed/kqs043.

45. Oomens PCJ, Huijs JJJM, Blonk RWB. Obstakels in werk: Wat belemmert werkhervatting bij werknemers met psychische klachten? [Obstacles in work: What impedes return-to-work in employees with mental health problems?]. Tijdschr Bedrijfs Verzekeringsgeneeskd. 2009;17(6):231-6.

46. Noordik E, Nieuwenhuijsen K, Varekamp I, van der Klink JJ, van Dijk FJ. Exploring the return-to-work process for workers partially returned to work and partially on long-term sick leave due to common mental disorders: A qualitative study. Disabil Rehabil. 2011;33(17-18):1625-35. http://dx.doi.org/10.3109 /09638288.2010.541547.

47. Rugulies R, Bültmann U, Aust B, Burr H. Psychosocial work environment and incidence of severe depressive symptoms: Prospective findings from a 5-year follow-up of the Danish work environment cohort study. Am J Epidemiol. 2006;163(10):877-87. http://dx.doi.org/10.1093/aje/kwj119.

48. Magnusson Hanson LL, Theorell T, Bech P, Rugulies R, Burr H, Hyde M, et al. Psychosocial working conditions and depressive symptoms among swedish employees. Int Arch Occup Environ Health. 2009 Aug;82(8):951-60. http://dx.doi. org/10.1007/s00420-009-0406-9.

49. Andrea H, Bultmann U, van Amelsvoort LG, Kant Y. The incidence of anxiety and depression among employees--the role of psychosocial work characteristics. Depress Anxiety. 2009;26(11):1040-8. http://dx.doi.org/10.1002/da.20516.

50. Koopmans PC, Roelen CA, Groothoff JW. Risk of future sickness absence in frequent and long-term absentees. Occup Med (Lond). 2008 Jun;58(4):268-74. http://dx.doi. org/10.1093/occmed/kqn040.

Received for publication: 19 February 2013 